observations have recently been repeated in another obese patient who received the diets in the reverse order ('Table 2). Each diet was given for 4 days and the biological assay was carried out on urine collected during the last 2 days of each dietary period. Ketogenic activity was present in the urine in the periods of low-carbohydrate diets and disappeared when the carbohydrate was increased, despite the persistent calorie deficit.

\title{
REFERENCES
}

Ashmore, J., Cahill, G. F. Jr. \& Hastings, A. B. (I960). Recent Progr. Hormone Res. 16, 547. Chalmers, T. M., Kekwick, A., Pawan, G. L. S. \& Smith, I. (I958). Lancet, i, 866.

Chalmers, T. M., Pawan, G. L. S. \& Kekwick, A. (1960). Lancet, ii, 6.

Engel, F. L. \& White, J. E. Jr. (1960). Amer. F. clin. Nutr. 8, 691.

Rudman, D. \& Seidman, F. (1958). Proc. Soc. exp. Biol., N.Y., 99, 146.

\section{Energy expenditure and calorie intake in young men}

By O. G. Edrolm, Division of Human Physiology, National Institute for Medical Research, Medical Research Council, c/o Medical Research Council Laboratories, Holly Hill, Hampstead, London, N.W.3

The determination of calorie balances in man requires accurate measurement of energy expenditure and food intake over a period of at least a week (Widdowson, Edholm \& McCance, 1954; Edholm, Fletcher, Widdowson \& McCance, 1955). In this country a number of surveys have been made of young men, during a period of military training. The food intake of sixty-four men was measured for 3 weeks, and the energy expenditure of thirty-five of these subjects was recorded (Adam, Best, Edholm, Fletcher, Lewis \& Wolff, I958; Adam, Best, Edholm, Goldsmith, Gordon, Lewis \& Wolff, 1959). In another experiment the food intake and energy expenditure of thirteen men were followed for a period of 14 days, but the food intake was restricted for part of the time and the results will be briefly described separately (Adam, Best, Edholm \& Wolff, r957).

It is the intention in this paper, not to give the full details of these various surveys, but to discuss the problem of arriving at an accurate measure of calorie balance, and the implications of present findings.

All who have attempted dietary surveys will agree that there are a large number of possible errors, especially when it is intended to do the study without interfering with the ordinary life of the subject. The measurement of energy expenditure may be liable to even more errors, because of the difficulty of having a continuous measurement throughout the day. An independent check on the results is obviously necessary, and the evident parameter to examine is body-weight. Daily weights were recorded in all these subjects, the weighing being done between 6.15 and 6.45 a.m. immediately after the subjects had got out of bed and had emptied their bladders. 
The results of all the surveys mentioned above show that there is a highly significant correlation between the daily calorie balance and the daily weight change. Such a finding lends credence to the belief that the calorie balance has been recorded with reasonable accuracy. There is, however, in spite of the overall statistical correlation a very wide scatter, and not infrequently a considerable fall in bodyweight from one day to the next, although a positive calorie balance has been recorded.

The pattern of daily weight changes has been examined, and there is considerable fluctuation. Such fluctuations are in excess of the error of weighing, which is approximately $\pm 25 \mathrm{~g}$. In most of the surveys the subjects were examined for three periods of I week each; in view of the fluctuations it was decided to continue weighings of one group of twelve men for a period of 7 weeks. In this period a weight change of more than $0.5 \mathrm{~kg}$ from one day to the next was recorded on over 100 occasions, and weight changes of I $\mathrm{kg}$ or more were observed on thirty occasions.

In the weekly surveys, similar large changes were observed with approximately the same frequency, and on these occasions measurements of daily calorie intake and expenditure were available. These large changes were not only too great to be accounted for by a calorie imbalance: on occasions the directions of the imbalance and of the weight change were opposite. There is a surprising lack of published information on daily weight changes, and it is possible that the large variations found in these young men, who were aged $17 \frac{1}{2}-24$ years, may be peculiar to this age group or to their average high level of energy expenditure. On the other hand, no relationship could be found between the level of energy expenditure and the occurrence of these large weight changes. It seems highly probable that an imbalance of water is the main factor responsible. However, the main point is that weight changes as a check on the accuracy of determinations of calorie balance may be misleading if water balance is not studied as well. This requirement considerably complicates the study of calorie balances. Nevertheless weight changes, over a sufficient period of time, are extremely important as indices of calorie balance. In the studies referred to above on young men, the calorie equivalent of weight change gives a value close to $7000 \mathrm{kcal} / \mathrm{kg}$ weight change. This figure is in agreement with the finding of Keys $\&$ Brožek (1953). It seems probable, therefore, that with the many possible sources of error in the measurement of intake and expenditure these errors in general cancel out.

The study of the young men was facilitated by their being under military discipline, and therefore it was relatively simple to have all the subjects under observation continuously without interfering with the pattern of their activities or of food intake. All the subjects were engaged in the same activities, and the same food was presented to them. It was expected that energy expenditure and food intake would be reasonably similar, and that subject difference would be small. A further reason for this expectation was the homogeneity of the group. The age range was small, and height and weight were also similar. But the results showed a very wide range both of intake and expenditure between individuals, and for any one individual from day to day. 
There was no correlation between intake and expenditure on a daily basis, although there was highly significant correlation on a weekly basis.

The techniques used for the measurement of food intake were based on the measurement of the food from the time it entered the kitchen until it reached the subject's plate. Plate waste was also measured by separating into components and weighing. Each serving of food was weighed and the composition of each dish was known. An observer was present at each table occupied by the subjects, and as soon as each course was eaten the plate waste was weighed. Apart from what they obtained in the Mess, the subjects could purchase food in the Navy, Army and Air Force Institute (N.A.A.F.I.). An observer was present in the N.A.A.F.I. to record all food purchased, and also to measure waste. During the period of observation the subjects did not go on leave. Food parcels received were also weighed; the food in them accounted for a very small, virtually insignificant, proportion of the total intake.

With few exceptions, the subjects gained weight, and weight changes were similar in other groups who were not being studied. It might be thought that the constant surveillance could have interfered with food habits, but there was no evidence of such interference, and the similarity of the weight change in control subjects supported this view.

The energy expenditure was measured directly and indirectly. A complete timeand-motion study was done throughout the day. For a considerable part of the day, the group of subjects engaged in identical activities, such as drilling. One of the techniques used has been described by Wolff (1958). The device consisted of a long box, along the top of which was a list of activities; under each item was a lamp, a button and a counter. An observer, using a walkie-talkie set, would inform the recorder that the squad were marching. The appropriate button was pressed and the counter started, ticking off each $\frac{1}{2}$ sec. After $2 \mathrm{~min}$, the signal was received that the squad had halted: the button marked 'standing' was pressed, and the first counter stopped and the second started. Over a I or a $2 \mathrm{~h}$ period, whichever was appropriate, a complete time record was obtained of the total time spent on each activity.

In addition, the oxygen consumption of the individual was measured with the Integrating Motor Pneumotachograph (I.M.P.) (Wolff, 1958). With this instrument ventilation volume can be measured for long periods, up to $3 \mathrm{~h}$, without interfering with the activity of the subject. An integrated gas sample is also obtained for analysis of the expired air. On some occasions the I.M.P. has been worn for 20 out of the $24 \mathrm{~h}$, but average use amounted to approximately $8 \mathrm{~h}$ a day. In calculating the energy expenditure the I.M.P. values were used when available, and the time-and-motion records for the remainder of the time. A table was made out for each subject, tabulating the time spent on each activity. When there was an appropriate value for a similar activity derived from the I.M.P. values it was used. The energy expenditure during sleep was estimated as equal to the basal metabolic rate (B.M.R.), which was determined on each subject on at least three occasions. When direct measurement was made during sleep, the mean value was always close to or identical with the B.M.R. 
For the remaining activities, for which there was no appropriate value, use was made of the figures for energy expenditure published by Passmore \& Durnin (1955) or of those obtained on previous surveys of military personnel (Edholm et al. $\mathrm{I} 955)$.

Surveys of this type require a large, well-trained team. With the advantages mentioned above, of studying subjects in a military setting, it is thought that it is possible to get a very close approximate to the actual calorie balance.

The overall range of intake, when individual man-days are studied, is from I000 to $8000 \mathrm{kcal}$. The range of expenditure is less, but is still considerable, from 2100 to $6500 \mathrm{kcal}$.

In the experiment in which there was a period of calorie deficiency, the subjects spent 4 days with normal activities and eating the food provided in the Mess, with access to the N.A.A.F.I. There were then 5 days spent in a very active field exercise, and during this time one group was given a ration which provided about $4000 \mathrm{kcal}$, and the second group had a ration of only $3000 \mathrm{kcal}$. There was no other source of food. After the exercise there was a period of 6 days of relative rest with food provided virtually ad lib.

Energy expenditure during the exercise was maintained at a level of $5000 \mathrm{kcal} /$ day, so when it was finished the first group had a deficit of $5000 \mathrm{kcal}$ and the second a deficit of $10000 \mathrm{kcal}$. The weight loss averaged I and $2 \mathrm{~kg}$ respectively. Water was freely and easily available throughout the field trial and water intake averaged over 3 1. a day. Urine volume was only measured on relatively few occasions, but was always small, of the order of $500-700 \mathrm{ml}$ in $24 \mathrm{~h}$. The weight loss was larger than could be predicted from the calorie deficit, on the basis of $7000 \mathrm{kcal} / \mathrm{kg}$ body-weight. During the rest period following the exercise, body-weight recovered rapidly and more quickly than indicated by the calorie balance. Water balance could not be measured during this period, but it seems highly probable that there was some dehydration during the exercise which was promptly corrected in the first $24 \mathrm{~h}$ after the exercise.

In the recovery period food intake was high in both groups providing on average $5000 \mathrm{kcal}$ each day for 5 days. 'The calorie intake was nearly similar in the two groups, $4850 \mathrm{kcal}$ in the group with the 10000 deficit, and 5200 in the one with the 5000 deficit. During this time energy expenditure in the two groups averaged $3200 \mathrm{kcal}$ a day.

It is interesting that the men with the smaller calorie deficit ate slightly more than the subjects with the bigger deficiency.

An important factor in the calculation of calorie requirements is that of the environmental temperature. Johnson \& Kark (1947) studied the calorie intake of American soldiers stationed in environmental temperatures ranging from $+35^{\circ}$ to $-30^{\circ}$, and found an inverse linear relationship between environmental temperature and calorie intake. There was a difference of nearly $2000 \mathrm{kcal}$ a day between the intakes of men in the coldest and hottest environments.

Since this study, undertaken during World War II, there has been a number of surveys of food intake, principally conducted in America on soldiers stationed in 
various climates. Energy expenditure has also been measured, and the results obtained do not show any striking relationship between temperature and intake. Welch, Buskirk \& Iampietro (1958) found a similar calorie intake in men stationed in Arizona in the summer, Churchill in Canada during the winter and Boston in the summer.

LeBlanc (1957), from a summary of the available literature, also concludes that there was no evidence of a relationship between environmental temperature and food intake. Rodahl (1954), in particular, found that food intake in the Canadian Arctic amongst trappers and Eskimos was relatively low in the winter and was certainly not higher than in the summer.

Consolazio, Konishi, Ciccolini, Jamison, Sheehan \& Steffen (r 960) have produced evidence that, far from calorie requirements in the heat being less than in temperate regions, they may even be higher.

In general, the conclusion from these numerous studies is that calorie requirements are not directly influenced by environmental temperature.

Apart from Rodahl's studies, all the surveys have been made on military personnel, whose activities were controlled. There is some information from measurements made on members of Polar expeditions. Masterton, Lewis \& Widdowson (I957) found that the energy expenditure of four subjects at the Base Camp in Northern Greenland averaged $3580 \mathrm{kcal}$ and the intake was approximately $300 \mathrm{kcal}$ higher. During sledging the expenditure rose to $5200 \mathrm{kcal}$, and food intake was about 400 kcal less. A. Rogers (I959, personal communication), in a careful study of one man during a week in the winter at an Antarctic base, recorded an energy expenditure of $4000 \mathrm{kcal}$ and the food intake was similar. N. Norman ( 1960 , personal communication) studied energy expenditure at another Antarctic base and his figures agree closely with those of Masterton et al. (1957), i.e. $335^{\circ} \mathrm{kcal}$ at base as anerage for the whole year, rising to $5000 \mathrm{kcal}$ during sledging.

Climate can impose a restriction on energy expenditure. In the heat, if energy expenditure is too high, body temperature will rise, and eventually collapse will ensue. In the cold, the conditions may be too severe to permit any outdoor activity. On Polar expeditions there is usually much physical work to be done, largely due to the environmental conditions. Indirectly, therefore, cold climates can increase food requirements, but with similar patterns of activity, calorie intake does not appear to be affected by environmental temperature.

Lewis, Masterton \& Rosenbaum (1960) also studied body-weight and found that there was a small seasonal change with a rise in the winter and a fall in the summer. Wilson (I960) measured the body-weight of seventeen members of an Antarctic expedition. He also found a seasonal fluctuation with a winter peak and lower values in the summer. Similar findings are reported from other unpublished studies in the Antarctic.

Apart from the seasonal change, body-weight remained, on the average, constant throughout the whole year.

The conclusions that can be reached as a result of studies of young men engaged in relatively strenuous work in different climates are: (I) There is no relationship 
between daily food intake and energy expenditure. (2) Body-weight can show marked fluctuations from day to day, probably due to a water imbalance. (3) In spite of these two findings over a period of time of a week or more, the food intake and energy expenditure are closely balanced and weight remains relatively constant.

The implications are that the factors controlling appetite are not related to immediate demands but are affected by a longer-lasting stimulus.

In extreme conditions with severe restrictions on intake, energy expenditure is certainly reduced. Nevertheless, the evidence suggests that under more usual conditions, appetite is controlled rather than activity. The nature of this control remains to be elucidated.

\section{REFERENCES}

Adam, J. M., Best, T. W., Edholm, O. G., Fletcher, J. G., Lewis, H. E. \& Wolff, H. S. (1958) Report to the Medical Research Council. M.R.C. $5^{8 / 201}$.

Adam, J. M., Best, T. W., Edholm, O. G., Goldsmith, R., Gordon, E. F., Lewis, H. E. \& Wolff, H. S. (I959). Report to the Medical Research Council. M.R.C. 59/8 I9.

Adam, J. M., Best, T. W., Edholm, O. G. \& Wolff, H. S. (1957). Report to the Medical Research Council. M.R.C. $57 / 93$.

Consolazio, C. F., Konishi, F., Ciccolini, R. V., Jamison, J. M., Sheehan, E. J. \& Steffen, W. F. (r960). Metabolism, 9, 435 .

Edholm, O. G., Fletcher, J. G., Widdowson, E. M. \& McCance, R. A. (1955). Brit. Ұ. Nutr. 9, 286.

Johnson, R. E. \& Kark, R. M. (1947). Science, 105, 378.

Keys, A. \& Brožek, J. (1953). Physiol. Rev. 33, 245.

LeBlanc, J. A. (1957). F. appl. Physiol. ro, 28 I.

Lewis, H. E., Masterton, J. P. \& Rosenbaum, S. (1960). Clin. Sci. 19, 55 r.

Masterton, J. P., Lewis, H. E. \& Widdowson, E. M. (1957). Brit. F. Nutr. 11, 346.

Passmore, R. \& Durnin, J. V. G. A. (1955). Physiol. Rev. 35, 801,

Rodahl, K. (1954). F. Nutr. 53, 575.

Welch, B. E., Buskirk, E. R. \& Iampietro, P. F. (1958). Metabolism, 7, I4I.

Widdowson, E. M., Edholm, O. G. \& McCance, R. A. (1954). Brit. F. Nutr. 8, I 47.

Wilson, O. (1960). Brit. F. Nutr. 14, 391.

Wolff, H. S. (1958). Quart. F. exp. Physiol. 43, 270.

Wolf, H. S. (1959). Ergonomics, 2, 354.

\section{Calorie requirements in human pregnancy}

By A. M. Thomson and F. E. Hytтen, Obstetric Medicine Research Unit (Medical Research Council), University of Aberdeen

Several professional, national and international organizations have made statements on the requirement or 'recommended allowance' of calories in human pregnancy. Yet, so far as we know, a reasoned account of the matter has never been published. This paper is a preliminary attempt to fill the gap. Our conclusions are provisional and, for reasons of space, we cannot present the sources of information and calculations in detail. We hope to publish a fuller account in due course, after more data have been collected.

\section{Theoretical basis}

An increase in the calorie requirement is created during pregnancy in the first place by the growth of the foetus and placenta, and the formation of the liquor 